\title{
Dictionary as a Major Resource for EFL Course in Pronunciation
}

\author{
Al-Sadig Ezza (Corresponding author) \\ Al-Majma’ah University, Saudi Arabia \\ E-mail: sadigss@yahoo.com \\ Zeina Saadeh \\ Editor, ATEL Journal, Lebanon \\ E-mail: zenasaadeh@yahoo.com
}

Received: January 5, 2011 Accepted: January31, 2011 doi:10.5430/wjel.v1n1p63

\begin{abstract}
Most if not all EFL syllabi at tertiary level in the Middle East include a number of phonetic courses that intend to improve learners' pronunciation of English. A variety of titles are used to name these courses: English Phonology, English Phonetics, Phonetics, Phonetics and Phonology, etc. As to the resources for these courses, many EFL departments fall back on textbooks such as Roach (2005), Gimson (1989), etc. This paper argues that the content of these textbooks is irrelevant to the training needs of most EFL learners per se at the beginning of their study of English Pronunciation. What these resources do is provide learners with phonetic information that ranges between sound production and perception. Thus, by the end of the course, most students become knowledgeable about phonetic theories, phonetic rules, criteria of sound classification and the like. Of course, little time is reserved for practicing phonetic transcription. Thus, instead of improving learners' pronunciation of English, these courses produce phoneticians who could not sometimes pronounce English even "approximatively". This paper proposes a phonetic course that focuses more on pronunciation practice and less on phonetic information in order to help students overcome their pronunciation difficulties. Thus, rather than using these textbooks as basic resources for a first course in English phonetics, the paper argues that only learners' dictionaries can provide such practice.
\end{abstract}

Keywords: Dictionary, Phonetics, Phonology, Pronunciation, Communication, Consonants, Vowels, Practice, Accent, Interlanguage, Segmental/supra-segmental sounds

\section{Introduction}

ELT literature abounds in a number of statements about the acquisition of English accent by non-native speakers. Other things being equal, English accent has always been considered a differentiating factor between adult native and non-native speech. Advocates of the interlanguage hypothesis have gone so far as to argue that no matter what the degree of competence of EFL learners, their speech will always be characterized by a foreign accent. For instance, Nemser (1984) conceives of the whole language system of EFL learners, including their pronunciation, as "approximative system”. Of course, the standard to measure such a system is the native linguistic competence.

Needless to say, mastery of the English pronunciation is a key to successful communication in all contexts of English use. Vitanova and Miller (2002) reported an ESL research subjects, conceiving that improving pronunciation is very helpful to my career, because the ability of verbal communication is very important to a nurse'. By contrast, it is widely argued that failure to produce correct English pronunciation '... can undermine learners' self-confidence, restrict social interactions, and negatively influence estimations of speaker's credibility and abilities' (Florez 1989). Indeed, it is likely that an EFL learner may take refuge into silence instead of mispronouncing a word in such as a way that may result in a negative estimation of their 'credibility and abilities'. Owing to the important role that the English (native or native-like) accent plays in oral communication, a number of ways have been employed to enable (adult) EFL learners to acquire it at least "approximatively". These include immersion programs, (natural) exposure to the language, (formal and informal) listening programs, and phonetic courses. Of course, all or many of these ways can be incorporated into the same educational program.

It has become common knowledge that the demonstration of workable English pronunciation requires acquisition of segmental and supra-segmental sounds. As to the role of these two sets of phonetic data, Florez (1989) reports that for a number of scholars "since supra-segmental elements provide crucial context and support (...) for segmental production, 
they are assuming a more prominent place in pronunciation instruction". This proposal tends to put more emphasis on the role of supra-segmental sounds in oral communication than on segmental sounds. However, there is a view to the contrary; viz. if segmental sounds are not properly pronounced, the supra-segmental sounds cannot help determine the meaning of the speech in question. For instance, In a Saudi college, an EFL teacher was once reported saying "Do you want me to do that first?" where the last word appeared more "fast" than "first", with the possibility of both interpretations. Thus, knowledge of the speech act of the sentence does not help explain the overall meaning of the sentence due to the confusion caused by the segmentally mispronounced "first". Moreover, research findings indicated that it is the mispronunciation of segmental sounds that results in undesirable real-world consequences. Vitanova and Miller (2009) reported an ESL medical student saying “... in another time, when a patient needed a blinder to dark the room, I told the aid and brought me a blender”. By contrast, a wrong production of some prosodic features, i.e. stress, can still leave interlocutors with a general clue about the meaning intended by the speaker.

\section{Learners' Dictionary}

Someone might wish to ask: What kind of dictionary that could simply replace the text-books mentioned above as a main resource for a first EFL course in phonetics? To begin with, the relevant literature includes a number of terms that refer to the type of dictionary compiled for EFL learners. Most frequent of these are "learner's dictionary", "advanced learners' dictionary", "good learners' dictionary", and "bilingual dictionary". It goes without saying that advanced learners' dictionaries are the most appropriate resources for all types of lexical information sought by EFL learners at tertiary level. However, the use of the adjective "advanced" is not a necessary condition for learners' dictionaries to be so perceived. A case in point is Longman Dictionary of Contemporary English (LDCE); it is certainly of the same coverage as the Oxford Advanced Learner's Dictionary (OALD), and is widely used by advanced EFL learners. Cowie (1989, p. 42) refers to both dictionaries to illustrate the concept of "learners' dictionaries" as "rightly perceived by students and teachers as information resources which combine the advantages of broad coverage, moderate size and relatively low cost”.

As to the notion of "good learner's dictionary", Taylor (1990, p. IV) points out that "good dictionaries provide so much necessary information for the language learner: definitions, grammatical information, indication of usage ... lexical structure and relationships, and encyclopedic information". A similar but more comprehensive characterization of a "good dictionary" is proposed by Crystal (1987, p. 111). Crystal puts forward that such a dictionary should provide answers to twenty learners' questions including, ineralia, its paper quality, binding, and lexical, cultural and encyclopedic information.

As shown in the few paragraphs above, the dictionary is a reliable resource for all types of lexical information that learners may look up. However, research findings indicate that the dictionary has most frequently been used for one piece of linguistic information, i.e. lexical meaning. For instance, Barnhart (1964, p. 458) reports that teachers in the USA "were asked to rate six types of information commonly given in terms of their importance to first year students". The results revealed that "the students used the dictionary most frequently for meaning". Two similar studies were also conducted into the use of the dictionary by native speakers and EFL learners by Longman in 1980 (Summer, 1988, p. 114). The first study investigated the use of the dictionary by native speakers in Britain; it was found out that the most frequent information looked up by the subjects was meaning. The second study was conducted by Longman ELT Dictionary Department into the use of LCDE by students at secondary and tertiary levels in Britain, Japan, Germany, USA, Mexico and Nigeria. Again the result showed that LCDE was often used to check meaning.

In the light of these research findings, advocates of the use of the aforementioned text-books as primary resources for first courses in English phonetics might argue that since learners seldom use the dictionary to check pronunciation, it would be pointless to propose a dictionary-based course in English phonetics. Despite the plausibility of the argument, a number of counterarguments can be developed in defence of the use of the dictionary as a primary resource for a first EFL course in English phonetics. First, pronunciation problems are more urgent than meaning problems. While learners can guess a word meaning from the context with a more approximate result, they cannot do so with pronunciation. Since pronunciation is an intrinsic characteristic of the individual word, context could not be expected to help learners overcome problems pertaining to it. Second, EFL learners could not always model their pronunciation on their teachers' since the latters also have their own pronunciation problems. Thus, what has come to be described as "language learner language" in the interlanguage literature also applies to some EFL teachers. Third, since language is open-ended phenomenon, both EFL teachers and learners need to fall back on the dictionary as the only reliable resource for correct pronunciation.

It seems that bilingual dictionaries are not in vogue in the writings of dictionary researchers. Support for this claim comes from Tickoo (1989, p. V). He contends that "learners' dictionary can be said to have three main attributes: it is 
derivative (based on established principles or practice), it is in most cases monolingual and it is principally a pedagogic resource. The second attribute detracts from the value of the bilingual dictionary and adds more to the controversy over its relevance to learners' needs.

\section{Dictionary as a Major Resource for Pronunciation}

This paper argues that a phonetic course should focus more on pronunciation practice and less on phonetic information in order to help the students overcome their pronunciation difficulties. Needless to say, textbooks that EFL departments adopt as course resources could not provide learners with valid pronunciation practice, which is argued to be primarily provided by learners' dictionary. The table below gives an outline of the items covered by a dictionary-based course alongside a list of items included in a traditional course:

\section{$<$ Table 1 about here $>$}

Before commenting on the content, it is appropriate to point out that we attempted an internet search for courses in English phonetics so as to know more about their specific objectives to realize whether or not they would confirm our argument that these courses concentrate on the acquisition of phonetic information at the expense of practice in correct pronunciation. Some EFL departments set realistic objectives (e.g. to introduce the students to the methods of description and classification of the English sounds) in the light of their respective course items that basically focus on phonetic information, such as speech physiology, classification of sounds, phonemic analysis, etc. On the other hand, online search has also shown that a number of such courses set objectives that focus on pronunciation practice while their content focuses on the acquisition of phonetic information. To show that this is so, consider the following course objectives:

- $\quad$ At the end of the course, the students should be able to produce, correctly pronounce and discriminate English vowels and consonants.

- The course should help the students acquire pronunciation without too many traces of [mother tongue] articulation and intonation.

- $\quad$... so that participants can not only improve their own pronunciation, but also make use of the theoretical information to guide their teaching practice.

- $\quad$ The main emphasis is on acquiring the practical ability to make and hear differences between sounds and to identify common pronunciation problems.

As can be seen in this list of objectives, despite the intentions to teach or to improve learners' pronunciation of English, the students end up mastering considerable body of phonetic information as if they were trained to be phoneticians. It seems that the only item that can help realize these course objective is "phonetic transcription". But the fact that the relevant courses have been accumulated with a myriad of phonetic information makes it virtually difficult to allow for enough practice in phonetic transcription.

As to the contents of the proposed dictionary-based course in English phonetics, they are apparently more relevant to the courses objectives just quoted. They basically address the importance of practice in improving learners' pronunciation with special emphasis on the most problematic areas as will be discussed in some detail below. What is more, it is reasonable to claim that this proposal emanates from the rationale for introducing the International Phonetic Alphabet (IPA) - since it attempts to bridge the gap between the English spelling system and the sounds corresponding to them.

Let us consider three items in the proposed course to see how practice can improve learners' pronunciation. The first such item is the "pronunciation of the English vowel letters". The significance of this component stems from the fact that the five English (vowel) letters of the alphabet unpredictively reveal themselves in twenty different vowel sounds (and some consonants) in ways that cannot be satisfactorily handled in a traditional course owing to the limited time allowed for phonetic transcription. An interesting description of the oddities of the English spelling is presented in a poem entitled "English is a tough stuff". The poem tries to show the abyss of mismatch between the graphological and phonological representations of the English sounds. The poem consists of nine stanzas and seventy-seven lines, apparently attempting to establish an inventory of problematic areas of the English letter-sound relationship. Below is the second stanza of the poem:

Just compare heart, beard, and heard,

Dies and diet, lord and word,

Sword, and sward, retain and Britain.

Now I surely will not plague you 
With such words as plague and ague.

But be careful how you speak:

Say break and steak, but bleak and streak;

Cloven, oven, how and low,

Script, receipt, show, poem and toe.

It would always be a wise decision to include such examples into the course materials that are intended to enhance learners' pronunciation of English. This poem can be an inspiring resource for pronunciation practice that beautifully fits in with the proposed dictionary-based course. Viz. with the aid of the dictionary, the poem can become a rich resource for classroom activities and homework. Course assignments can culminate in recitation of whole stanzas following sufficient preparations. Since the course is practice-oriented, much time can be devoted to the activities pertaining to this poem. By contrast, it would be impractical to waste a traditional course time on dealing with this poem. Rather such (precious) time could best be employed in informing learners about the physiology of speech, description and classification of the English sounds and the like.

The second course item to consider is "pronunciation of geographical names". This item deals with acquainting the students with the correct pronunciation of the names of continents, countries and cities across the globe. If EFL departments in the some Middle East universities are to base their teaching literally on, say, Roach (2005), then they cannot be expected to consider learners' need for correct pronunciation of the geographical categories just mentioned. Indeed, geographical names are extremely peripheral compared the phonetic rules, distinctive features, syllable structure, etc from the point of view of such text-books. This paper assumes that introducing learners to the pronunciation of place names can have a great communicative value in an age characterized by strong (academic) bonds. Participants at international conferences will facilitate passport officers' job at airports if they can correctly pronounce their destinations. It is unfortunate that traditional phonetics courses leave learners to take care of this problem for themselves. However, the proposed course has special interest in the correct pronunciation of place names. Soarmed with some advanced learners' dictionary, students can spend a considerable amount of class and free time transcribing place names. This procedure is particularly important in the Arab world. The speakers of Arabic as L1 hold the belief that "anything goes" in pronouncing foreign, non-Arabic, forms. Thus, having this sociolinguistic belief, reinforced by the fact that traditional courses neglect this phonetic skill would eternalize learners' ignorance of the correct pronunciation of place names.

The third component that the proposed course emphasizes is "selected areas". Such a selection may includeineralia, homophones, the regular past tense and plural markers. For, instance, ability to pronounce homophones will result in enhancing learners' knowledge of the relationship between the English vowel letters and the vowel sounds corresponding to them. In a traditional phonetics course, these items are briefly treated as part of phonetic transcription. As to the regular tense and plural markers, they cause a lot of problems for the speakers of Arabic as L1. For instance, in Saudi Arabia, most college students pronounce every letter in the word, so "booked" is pronounced as /bukit/ rather /bukt/. Thus, it is with intensive practice that learners can improve their pronunciation of these forms of the English spelling.

\section{Conclusion}

This paper has been an attempt to emphasize the significance of EFL learners' dictionary as a basic resource for a first EFL course in English phonetics. This approach is conceived to be more effective than the textbook-based phonetics courses in dealing with the learners' pronunciation problems. Thus, in this first courses, instead of studying, say, speech physiology and phonetic rules, a variety of activities have been proposed to form the backbone of classroom activities, ranging from pronunciation of the letters of the alphabet to phonetic transcription of whole paragraphs. However, the paper does not intend to detract from the role of textbook-based phonetics courses in introducing EFL learners to English pronunciation. It simply argues that this role should be postponed until learners come to grips with the essentials of English pronunciation through intensive practice of phonetic transcription. This stage of dictionary-based instruction has repeatedly been referred to by this paper as "a first course in English pronunciation”. 


\section{References}

Barnhart, C. L. (1964). Problems in Editing Commercial Monolingual Dictionaries. In Allen, H. B. (ed.): Readings in Applied Linguistics.Appelton-Century-Crofts. pp. 457-457.

Cowie, A. P. (1989). Learners’ Dictionaries- Recent Advances and Developments. In M. L. Tickoo (ed.): Learners’ Dictionaries: State of the Art. Seameo (Singapore): Regional Language Centre. pp. 42-72.

Crystal, D. (1987). The Cambridge Encyclopedia of Language. Cambridge: Cambridge University Press.

Florez, M. C. (1989). Improving an Adult ESL Learners' Pronunciation Skills.National Centre for ESL Literacy Education. Retrieved fromhttp://www.cal.org/caela/esl_resources/digests/pronun.html

Gimson, A. C. (1989). An Introduction to the Pronunciation of English. London: Edward Arnold

Nemser, W. (1984). An Approximative System of Foreign Learners. In J. Richards (ed.): Error Analysis: Perspectives on Second Language Acquisition pp. 55-63. Singapore: Longman.

Piotrowski, T. (1989). Monolingual and Bilingual Dictionaries: Fundamental Differences. In M. L. Tickoo (ed.): Learners' Dictionaries: State of the Art.Seameo (Singapore): Regional Language Centre. pp. 72-83.

Roach, P. (2005). English Phonetics and Phonology: A Practical Course. Cambridge: Cambridge University Press

Summer, D. (1988). The Role of Dictionaryin Second Language Learning. In R.Carter and M. McCarthy (eds.): Vocabulary and Language Teaching. pp. 111-125. London: Longman.

Taylor, L. (1990). Teaching and Learning Vocabulary.Hempstead: Prentice-Hall International.

Tickoo, M. L. (1989). Introduction. In Tickoo M. L. (ed.): Learners’ Dictionaries: State of the Art.Seameo (Singapore): Regional Language Centre. pp. v-xvi

Vitanova, G. and Miller, A. (2002). Reflective practice in pronunciation learning.TheInternet TESOL Journal, Vol. VIII, No. 1, January. Retrieved 14 October, 2004, Retrievedfromhttp://iteslj.org/Articles/Vitanova-Pronunciation.html.

Table 1: Contents of dictionary-based Course

\begin{tabular}{|l|l|}
\hline Dictionary-based Course & Textbook-based Course \\
\hline English Sounds: Consonants & Types of Phonetics \\
\hline English Sounds: Vowels & Phonetics and Phonology \\
\hline Pronunciation of the Letters of Alphabet & Organs of Speech \\
\hline Pronunciation of the English Vowel Letters & Places of Articulation \\
\hline Pronunciation of Vowel Combinations & Manners of Articulation \\
\hline Letter-Sound Relationship & Voicing \\
\hline Pronunciation of Geographical Names & English Consonants \\
\hline Phonetic Transcription: Word Level & English Vowels \\
\hline Phonetic Transcription: Sentence Level & Phonological Processes \\
\hline Phonetic Transcription: Paragraph Level & Phonetic Transcription \\
\hline Selected Areas: homophones, tense and number markers, minimal pairs etc. & Syllable Structure \\
\hline
\end{tabular}

